\title{
PUBLICACIONES SOBRE LITERATURA FRANCESA EN ESPAÑA, 1989
}

Alicia Yllera

UNED

\section{Obras colectivas}

Cuadernos de Filología Francesa, Cáceres, 3, 1989.

Estudios franceses, Salamanca, 5, 1989.

Estudios de lengua y literatura francesas, Cádiz, 3, 1989.

Georges Bernanos 1888-1989, Mallorca, Ediciones del Estudi General de Mallorca, 1989.

Homenaje al Profesor Luis Rubio. T. I y II. Estudios Románicos, vol. 4 y 5 (1987-88-89), Murcia.

Imágenes de Francia a'n las letras hispánicas, ed. F. Lafarga, Barcelona, PPU, 1989.'

Investigación franco-española, 1, 1988 (1989), Córdoba.

L'Ull critic 1, 1989, L'Adéu a Adrià. Homenatge a Marguerite Yourcenar, Lérida.

' No se desglosan las diversas colaboraciones publicadas en esta obra. 
Marguerite Yourcenar, Biographie, Autobiographie, ed. Elena Real (Actas II Congreso Internacional organizado por el Departamento de Filología Francesa de la Univ. de Valencia, 1986), Valencia, Servicio de Publicaciones de la Univ. de Valencia, 1988.

Queste, Universidades del País Vasco, Pau, Valencia, Zaragoza, 4, 1988 (1989).

Retorno de Hermes: hermenéutica y ciencias humanas (El), ed. A.

Verjat, Barcelona, Anthropos, 1989.

Textos, 1989 (1990), «Mito-ficción-lecturas», Zaragoza.

Villiers de L'Isle-Adam: l'home, la realitat, la ficció, ed. Marta Giné i Janer, Lérida, Virgili \& Pagès, Publicaciones del Estudi General de Lérida, 1989.

\section{Edad Media}

Aguiriano BARrón, Begoña, "Le lyrisme de l'amour naissant dans Erec et Enide et Le Chevalier au lion", Queste, 4, 1988 (1989), pp. 7-19.

Aragón Fernández, M. ${ }^{a}$ Aurora, «La afectividad en el lenguaje épico: la expresión de la cólera", Homenaje al Pr. Rubio, I, pp. 85-93.

Aramburu Riera, Francisca, "La Ville de Constantinople dans une chanson de geste française», Actes du sixième Congrès des Etudes du Sud-Est européen, 1989.

- El Héroe y el cosmos, Publ. de la Universidad de Murcia, 1989.

Carmona Fernández, Fernando, «El horizonte temático de la obra literaria», Homenaje al Pr. Rubio, I, pp. 189-195. 
CARmona Fernández, Fernando, «Ideología y fantasía en la roman en verso del siglo XIII", Literatura y fantasia en la Edad Media, Publicaciones de la Univ. de Granada, 1989, pp. 41-61.

Flores, Camilo, $O$ Cantar de Roldán, texto y traducción gallega, Santiago, Xunta de Galicia, Servicio Central de Publicacións, Clásicos en galego n. ${ }^{\circ} 3,1989$.

Flores ArRoyuelo, Francisco J., «Pasado y presente en los Romans d'Antiquité», Homenaje al Pr. Rubio, I, pp. 373-387.

Martínez Perez, Antonia, «Análisis del único ejemplo conocido de fatras imposibles en un contexto posible: los fatras de Jean Regnier», Homenaje al Pr. Rubio, II, pp. 907-918.

- El teatro de Adam de la Halle: "Le Jeu de la Feuillée» y le "Jeu de Robin et Marion», trad., intr. y notas. Univ. de Murcia, 1989.

MuÑoz ZielinsKI, M. ${ }^{\text {a }}$ Teresa, «Aproximaciones al tema de la naturaleza en la poesía de la Edad Media», Homenaje al Pr. Rubio, II, pp. 1057-1063.

RIQUER, Isabel DE, «Nuevas publicaciones sobre lírica trovadoresca», Filología Románica, 5, 1987-1988, pp. 303-315.

- «El juego de la decapitación», Literatura y fantasia en la Edad Media, J. Paredes (ed.), Granada, Universidad, 1989, pp. 117 139.

- «Noves publicaciones sobre lirica trobadoresca», Llengua i Literatura (Barcelona), 3, 1988-1989, pp. 427-444.

Riquer, Martín DE e Isabel DE, El Cuento del Grial de Chrétien de Troyes y sus continuaciones, intr. y trad., Madrid, Siruela, 1989.

SAnsonetTi, Paul-Georges, «El Hermes del Grial», El Retorno de Hermes, pp. 152-163.

YLLERA, Alicia, «Rutebeuf y la tradición del debate medieval», Homenaje al Pr. Rubio, II, pp. 1493-1503. 


\section{Siglo XVI}

Clementson, Carlos, «Tres elegías de Ronsard», Homenaje al Pr. Rubio, I, pp. 257-268.

DomíngueZ, Antonio, "Garcilaso, Ronsard y Herrera», Investigación franco-española, 1, 1988 (1989), pp. 111-125.

González Alcaraz, José Antonio, «Le débat féministe à la Renaissance», Homenaje al Pr. Rubio, I, pp. 453-460.

MARTíneZ, Caridad, "Quelques travaux récents sur Ronsard en Espagne», Ronsard en son quatrième centenaire, Genève, Droz, 1988, I, pp. 187-189.

Picazo, Dolores, «La modernité autobiographique des Essais», Bulletin de la Société des amis de Montaigne, 11-12, 1988, pp. 51-62.

\section{Siglo XVII}

BoIXAREU, Mercedes, Fonction de la narration et du dialogue dans "La Princesse de Clèves», Paris, Lettres Modernes, 1989.

Descotes, Maurice, «Sur trois odes de Racine», Queste, 4, 1988 (1989), pp. 21-31.

Hernández Rodriguez, Francisco Javier, El Avaro. El enfermo imaginario de Molière, trad. et intr., Madrid, Cátedra, 1989.

Ruiz Alvarez Rafael, «Análisis del diálogo en Le Prince Corsaire de Paul Scarron», Estudios humanisticos (Universidad de León), $10,1989$. 


\section{Siglo XVIII}

Aguilá Solana, Irene, «Consideraciones sobre la relación música-teatro en Tarare de Beaumarchais", Queste, 4, 1988 (1989), pp. 145-159.

CoTs, Montserrat, "Lesage traductor del Quijote de Avellaneda», Actas del VI Simposio de la Sociedad Española de Literatura General y comparada (Granada, 13-15 de marzo de 1986), ed. J. Paredes y A. Soria, Univ. de Granada, 1989, pp. 251-258.

DomínǴuez, Antonio, «Las Lettres Persanes y las Cartas Marruecas. La función de la perspectiva en la crítica social de dos novelas epistolares», Imágenes de Francia en las Letras Hispánicas, pp. 47-57.

Gabaudan, Paulette, «Rousseau et Révolutions», Estudios Franceses, 5, 1989, pp. 41-58.

LAFARGA, Francisco, "Voltaire en Espagne, 1734-1835», Studies on Voltaire and the Eighteenth Century, 261, Oxford, The Voltaire Foundation, 1989.

LÓPEZ VAlero, Armando, «Sensaciones y sentimientos en Les Rêveries du promeneur solitaire de Jean-Jacques Rousseau», Homenaje al Pr. Rubio, II, pp. 771-783.

MARTinez Dengra, Esperanza, «El vestuario del siglo XVIII según Marmontel», Homenaje al Pr. Rubio, II, pp. 889-897.

Pérez Pérez, M. Concepción, "Construcción y mecánica del cuerpo libertino en Sade. Experiencia del deseo», Philologia Hispalensis (Sevilla), 4 (1989), pp. 735-746.

SaURA, Alfonso, «Houdar de La Motte y el joven Voltaire», Homenaje al Pr. Rubio, II, pp. 1307-1321.

Tolivar Alas, Ana Cristina, "Traducciones y adaptaciones españolas de Racine en el siglo XVIII", Investigación franco-española, 1, 1988 (1989), pp. 177-190. 
TORRE GimÉnEz, Estrella de la, «Los libros clandestinos en Francia en el siglo XVIII", De la Ilustración al Romanticismo. III. Encuentros: ideas y movimientos clandestinos, Cádiz, 1988, pp. 287-294.

\section{Siglo XIX}

Alonso García, Ana, "Apuntes sobre el prometeismo maldororiano», Textos, 1989 (1990), pp. 3-18.

Alonso Seoane, M. ${ }^{a}$ José, «Una desconocida traducción española de L. D’Ussieux La Heroina francesa, de Vicente Rodríguez de Arellano", Investigación franco-española, 1, 1988 (1989), pp. 9-30.

ANOLL I VENDRELL, Lidia, "Villiers entre la dietètica i l'ecologia: una historieta del segle XIX", Villiers de Isle-Adam: l'home, la realitat, la ficció, pp. 153-162.

BASTIDA, Vicente, "Consideraciones sobre el héroe en el siglo XIX francés», Homenaje al Pr. Rubio, I, pp. 137-142.

Bravo Castillo, Juan, «Torture et espérance chez Poe et Villiers de l'Isle-Adam: l'horreur à la frontière du fantastique", Villiers de l'Isle-Adam: l'home, la realitat, la ficció, pp. 231-244.

CANTERA ORTIZ DE URBinA, Jesús, «La formación bíblica de Villiers de l'Isle-Adam. En los Contes Cruels y Claire Lenoir", Villiers de l'Isle-Adam: l'home, la realitat, la ficció, pp. 105-118.

CASADO, Loreto, «Imágenes de la alteridad en Le Bonheur dans le crime de Barbey d'Aurevilly", Estudios de lengua y de literatura K10 (Cádiz), 2.

CoQuio, Catherine, «La fin d'un lyrisme», Queste, 4, 1988 (1989), pp. 33-47. 
ElósEgUI, Teresa, «Comparación y metáfora: procedimientos de refuerzo en la expresión de la afectividad negativa en Madame Bovary", Textos, 1989 (1990), pp. 85-95.

FoucART, Claude, "La Révolte: les "instants indéfinissables" de la vie d'une femme», Villiers de l'Isle-Adam: l'home, la realitat, la ficció, pp. 69-80.

GARGUILO, René, «Les trois couleurs du comte Villiers de l'IsleAdam: le blanc, le noir et le rouge», Villiers de l'Isle-Adam: l'home, la realitat, la ficció, pp. 39-60.

GoNZÁlez SALVADOR, Ana, «Fantastique et fiction ( $L^{\prime} E v e$ future de Villiers de l'Isle-Adam I)", Villiers de l'Isle-Adam: l'home, la realitat, la ficció, pp. 199-209.

GINE JANER, Marta, "Théophile Gautier et Villiers de l'IsleAdam», Bulletin de la Société Théophile Gautier, 11 (1989).

- «Villiers de l'Isle-Adam. Les imatges de l'orgull a l'obra poètica i teatral", Villiers de l'Isle Adam: l'home, la realitat, la ficció pp. 81-92.

Guichardet, Jeannine, «De La Comédie Humaine aux Contes cruels: Balzac "annonciateur" de Villiers?», Villiers de l'ssleAdam: l'home, la realitat, la ficció, pp. 245-260.

Giochet-Juanny, Sylvie, «Le mythe de l'actrice dans $L ' E v e$ future", Villiers de l'Isle-Adam: l'home, la realitat, la ficció, pp. 177-197.

Hernández, Francisco Javier, «Ecos de la fiesta "Paris-Murcia" en $A$ la Recherche du temps perdu I", Homenaje al Pr. Rubio, I, pp. 563-568.

JovE, Jordi, «Las Evas futuras: Fuera del tiempo y en la caja de 
la inmortalidad», Villiers de l'Isle-Adam: l'home, la realitat, la ficció, pp. 165-176.

LAFARGA, Francisco, «La réception de l'oeuvre de V. Hugo en Catalogne", Le Rayonnement international de V. Hugo. Actes du Symposium de l'Association Internationale de Littérature Comparée. XI Congrès International (Paris, août 1985), Berna, Peter Lang Verlag, 1989, pp. 61-73.

Leal DuART, Julio, «Marguerite Gautier: de la mythologie à la mythomanie», Queste, 4, 1988 (1989), pp. 161-175.

MARIÑo, Alicia, «La trascendencia en lo fantástico: Villiers de l'Isle-Adam", Villiers de l'Isle-Adam: l'home, la realitat, la ficció, pp. 211-228.

Mateo Ballorca, Julián, «Maurice de Guérin o los rumores de la vida interior», Barcarola (Albacete), 31/32, 1989, pp. 107128.

OrTIZ, José, «Las Funciones del discurso y sus consecuencias en los Trois Contes de Flaubert», Textos, 1989 (1990), pp. 65-83.

Palacios Bernal, Concepción, «El feminismo de Henri Beyle: Stendhal y Lamiel», Homenaje al Pr. Rubio, II, pp. 1087-1095.

Parra I Albà, Montserrat, "Lèxic i sintaxi a L'Annonciateur de Villiers", Villiers de l'Isle-Adam: l'home, la realitat, la ficció, pp. 145-151.

Plantier, René, «L'Espagne dans l'oeuvre de Villiers de l'IsleAdam", Villiers de l'Isle-Adam: l'home, la realitat, la ficció, pp. 273-280.

PONT, Jaume, "Villiers per Ramón Gómez de la Serna», Villiers de l'Isle-Adam: l'home, la realitat, la ficció, pp. 293-304.

Prado, Javier DEL, "Consciente fin de siècle chez Mallarmé», Villiers de l'Isle Adam: l'home, la realitat, la ficció, pp. 307-337.

Prado, Javier del y Millán, José Antonio, Prosas de Mallarmé, trad., notas y estudio preliminar, Madrid, Alfaguara, 1988.

PRZYBOS, Julia, "Impatience de la foule ou l'histoire selon Villiers", Villiers de l'Isle-Adam: l'home, la realitat, la ficció, pp. 129-134.

RaITT, Alan, "Villiers de l'Isle-Adam en 1989», Villiers de l'IsleAdam: l'home, la realitat, la ficció, pp. 9-13. 
RaITT, Alan, "Villiers de l'Isle-Adam histrion véridique de luimême», Villiers de l'Isle-Adam: l'home, la realitat, la ficció, pp. 17-38.

Rodríguez Navarro, V., "Oeone y Goriot: de la maternidad perniciosa al cristo de la paternidad", Estudios Franceses, 5, 1989, pp. 103-117.

Rovira, Pere, «El Don Juan de Villiers», Villiers de l'Isle-Adam: l'home, la realitat, la ficció, pp. 63-67.

Roux, Suzanne, «La citadine et le monde du travail chez Zola: cas particulier des vendeuses dans $A$ u bonheur des dames", Homenaje al Pr. Rubio, II, pp. 1229-1236.

Santa I Banyere, M. angels, «De Spirite de Gautier a Véra de Villiers de l'Isle-Adam", Villiers de l'Isle-Adam: l'home, la realitat, la ficció, pp. 261-269.

SOLÀ SOLÉ, Pere, «La enunciación en L'Intersigne de Villiers», $V i$ lliers de l'Isle-Adam: l'home, la realitat, la ficció, pp. 135-144.

Solé I CASTElls, Cristina, «La nit a Axël», Villiers de l'Isle-Adam: l'home, la realitat, la ficció, pp. 93-101.

Tovar, Francisco, «La última Eva futura. Villiers de l'Isle-Adam en Rafael Cansinos-Asséns", Villiers de l'Isle-Adam: l'home, la realitat, la ficció, pp. 281-291.

Usó BALLESTER, María Dolores, «Le mécanisme de la révélation dans Le Convive des dernières fêtes de Villiers de l'Isle-Adam», Villiers de l'Isle-Adam: l'home, la realitat, la ficció, pp. 119-128.

VALLEJo RodrigueZ, Mercedes, «La ville dans la trilogie de Jacques Vingtras", Les Amis de Jules Vallès, 9, 1989, pp. 47-55.

- «Dos traducciones de L'Enfant de Jules Vallès», Fidus Interpretes, II, Univ. de León, 1989, pp. 258-266.

Verjat MassmanN, A., «En torno a Victor Hugo», Romanticismo/Romanticismos, ed. M. Siguan, Barcelona, P.P.U., 1988, pp.177-203. 


\section{Siglo XX}

ANOLL, Lidia, «Le monde n'est pas fait pour les anges. A propos de La Joie de G. Bernanos», Georges Bernanos, 1888-1988, pp. 9-26.

Bargallo Carrate, Juan, Don Juan. Hijo de nadie de Henry de Montherlant, trad. et intr., Madrid, Cátedra, 1989.

BENOIT MORINIĖRE, Claude, "La logique de l'histoire dans L'herbe de Claude Simon», Queste, 4, 1988 (1989), pp. 99-106.

- "Crisis y transgresión en las novelas de Marguerite Yourcenar", Barcarola (Albacete), julio 1988, pp. 189-203.

- «La Nouvelle Eurydice ou la labyrinthe du moi», Marguerite Yourcenar, Biographie, Autobiographie, pp. 65-69.

- "Le Pont des Sorts de Joseph Peyré: une réflexion sur le temps et l'espace sous le signe de la guerre civile», Literatura y Guerra Civil, ed. A. Santa, Barcelona, PPU, 1988, pp. 179-187.

- «Marguerite Yourcenar: de la première personne à la troisième personne", Bull. Soc. Int. d'Etudes Yourcenariennes, 3, 1989, pp. $35-51$.

BenoIT Morinière, Claude y André Courribet, «Représentation de deux pièces de Jean Tardieu en Espagne: Le Guichet et la Serrure», Lire Tardieu, 1988, pp. 27-33.

BERMÚdez MEdinA, Dolores, «Acotaciones a los movimientos de los personajes de la obra de Eugène Ionesco", Guiniguada (La Laguna), 4, pp. 27-41.

- Análisis simbólico del teatro de Ionesco, Cádiz, Publicaciones de la Univ. de Cádiz, 1989. 
BERmúdez Medina, Dolores, «Rostros de sombra: las máscaras en Jean Lorrain", Cuadernos de filologia francesa, 3, 1989, pp. 7-23.

BuENo, Juan Manuel, "Un tratado de la condición humana», L'Ull critic, 1, 1989, pp. 15-26.

CaAmaño, M." Angeles, «Una reflexión bajo el signo de Hermes: los manifiestos del surrealismo", El Retorno de Hermes, pp. 226-243.

Caballé, Anna, «Alexis o el aticismo de estilo", L'Ull critic, 1, 1989, pp. 10-14.

Camarero, Jesús, «Les hétérogrammes de Georges Perec, contrepoint formel du lyrisme», Queste, 4, 1988 (1989), pp. 49-65.

- «Un cas d'intertextualité inscriptive dans La vie mode d'emploi de Georges Perec», Cuadernos de filología francesa, 3, 1989, pp. 25-38.

Camero Pérez, Carmen, "Grande et petite nouvelle chez Bernanos", Bernanos 1888-1988, Estudi General Lul.lià, Palma de Mallorca, 1989, pp. 69-77.

Camero Pérez, Carmen y Goujon, Jean-Paul, «Pierre Louÿs y Andalucia. Nuevas cartas inéditas», Philologia Hispalensis (Sevilla), 4, 1989, pp. 767-778.

Carriedo, Lourdes, La Modificación de Butor, trad., ed., notas y estudio preliminar. Madrid, Cátedra, 1988.

- «La poética de Jules Supervielle, metáfora y metamorfosis», Barcarola (Albacete), 22/23, 1988, pp. 59-69.

CASADO, Loreto, «Ton majeur et mineur dans le lyrisme de Julien Gracq», Queste, 4, 1988 (1989), pp. 67-75.

- Memorias de un amnésico y otros escritos de E. Satie, trad. e intr., Madrid, Eds. Fugaz, 1989.

Diego Martínez, Rosa DE, «Description et peinture dans l'oeuvre de Claude Simon», Queste, 4, 1988 (1989), pp. 107-120.

Dominguez, Antonio, «Horizontalidad y verticalidad en $\mathrm{Le} \mathrm{Pa}$ lace", Queste, 4, 1988 (1989), pp. 121-132. 
FERnández CARdo, José María, «Sobre la poética del misterio en la narrativa francesa contemporánea", Cuadernos de filologia francesa, 3, 1989, pp. 39-55.

Flores GaRCia, A., «La création poétique chez Alain Fournier: le miracle de la fermière», Estudios Franceses, 5, 1989, pp. $29-40$.

Gamoneda LANZA, A., «Desierto, espejismo y texto. Una lectura de Cholodenko, Djaout, Le Clézio y Tournier", Estudios Franceses, 5, 1989, pp. 59-68.

García Gallego, Jesús, «La réception du surréalisme en Espagne (1924-1936). (La critique des revues littéraires en castillan et catalan)», Queste, 4, 1988 (1989), pp. 89-98.

GARCIA GOMEZ, Manuel, «Beckett: una degradación liberadora», Homenaje a Belloch Zimmermann, Cuadernos de Filologia (Valencia), 1988.

García Larrañaga, M. ${ }^{a}$ Asunción, «Estudio sobre la diversidad de los mitos en la obra de Francis Jammes», Textos, 1989 (1990), pp. 19-44.

GARGuILo, René, «Marguerite Yourcenar et l'Espagne», L'Ull critic, 1, 1989, pp. 57-69.

Gastón, Luis, «Biographie, autobiographie et roman chez $\mathbf{M}$. Yourcenar", Marguerite Yourcenar, Biographie, Autobiographie, 1988.

- «Claude Simon - Marcel Proust: deux narrations, une mémoire. Discours romanesque, mémoire effectiven, Actas del Congreso Internacional de Literatura Comparada, Univ. de Granada, 1989, pp. 199-207.

González Hernández, A. T., «Tueur sans Gages. Un exemple de la dynamique de la descente dans le théâtre d'Eugène Ionesco», Estudios Franceses, 5, 1989, pp. 69-83.

González SAlvador, Ana, "Anabase: analecture», Anuario de estudios filológicos (Univ. de Extremadura), 10, 1988. 
Goulet, A., «Le jeu des tropismes Sarrautiens», Estudios Franceses, 5, 1989, pp. 85-96.

Hernández Álvarez, V., "Les mots de Sartre, psychanalyse et intertextualité», Estudios Franceses, 5, 1989, pp. 97-102.

HeRnÁndez Rodríguez, Francisco Javier, «Por el camino de Swann o la redención por el arte», Barcarola (Albacete), 29, 1988, pp. 187-198.

IÑarRea Las Heras, I., "Les Nègres de Jean Genet: la Corte como espejo de un doble vacion, C.I.F., XV, 1-2, 1989, pp. 117124.

Jiménez Plaza, Dolores, «... l'amour qui fait tant souffrir...", Dossier Marguerite Yourcenar, Barcarola, (Albacete) julio 1988, pp. 205-216.

- «De l'illusion autobiographique à l'autobiographie partielle: stratégies du silence», Marguerite Yourcenar, Biographie, $A u-$ tobiographie, pp. 213-219.

Leal Duart, Julio, "La Passion du Général Franco d'Armand Gatti o grandeza y miseria del teatro militante», Literatura $y$ guerra civil, ed. A. Santa, Barcelona, PPU, 1988, pp. 43-52.

LEGUEN, Brigitte, «Muerte y suicidio en la obra de Drieu la Rochelle», Epos, 4, 1988, pp. 285-298.

LeNOIR, Françoise, "Viernes, día de Venus, día de Mercurio», $E l$ Retorno de Hermes, pp. 205-225.

LEPINETTE, Brigitte, «Les romans de San-Antonio ou un art (?) de la digression", Queste, 4, 1988 (1989), pp. 177-189.

LINARES LARA, Inmaculada, «Una escritura esquizoide: las novelas marroquíes de expresión francesa", Homenaje a Belloch Zimmermann, Cuadernos de Filologia (Valencia), 1988, pp. 233240. 
LINARES LARA, Inmaculada, «Mémoire et souvenir dans Comme l'eau qui coule", Marguerite Yourcenar, Biographie, Autobiographie, pp. 29-37.

Luengo Alburquerque, Elisa, "Le cocon comme mythe personnel chez Jacques Sternberg», Anuario de estudios filológicos (Univ. de Extremadura), 10, 1988.

Martín Hernández, Ramiro, "Lecture d'un poème d'Apollinaire: "Crépuscule"», Anuario de estudios filológicos (Univ. de Extremadura), 10, 1988.

Miñano Martínez, Evelio, «Lorand Gaspar: regard et réseau», Queste 4, 1988 (1989), pp. 77-88.

- «Les Charités d'Alcippe o el universo entretejido», Barcarola, (Albacete), julio 1988, pp. 217-230.

- "Chant funèbre pour les cadets de l'Alcazar: un conflit par ses signes", Literatura y guerra civil, ed. A. Santa, Barcelona, PPU, 1988, pp. 189-199.

- «Feux: les labyrinthes de l'effacement», Marguerite Yourcenar, Biographie, Autobiographie, pp. 29-37.

Monleón Domínguez, Ana, "Le miroir florentin», Marguerite Yourcenar, Biographie, Autobiographie, pp. 195-203.

MuÑoz Romero, Maria, "Jules Supervielle, le rêveur attentif», Philologia Hispalensis (Sevilla), 4, 1989, pp. 759-766.

Ortiz Domingo, José, "La fuerza hechicera del lenguaje en la narrativa de A. P. de Mandiargues», Queste, 4, 1988 (1989), pp. 191-208.

PAgÁn LóPeZ, Antonia, «Aventura, sueño y magia en Le grand Meaulnes, de Alain Fournier», Homenaje al Pr. Rubio, II, pp. 1079-1086.

Porras Medrano, Adelaida, «Un ejemplo de percepción diacrónica del espacio: La colline inspirée de Maurice Barrès", Philologia Hispalensis (Sevilla), 4, 1989, pp. 747-757. 
Prado, Javier DEL, Un amor de Swann, estudio preliminar, Madrid, Cátedra, 1988, pp. 9-102.

- «Proust y la necesidad hermanéutica», Barcarola, (Albacete), 1988, 29, pp. 159-183.

PRIM, Antoni, «Imatges clàssiques a l'obra de Marguerite Yourcenar", L'Ull critic, 1, 1989, pp. 71-75.

ReAl Ramos, Elena, «Marguerite Yourcenar y la insularidad», Barcarola (Albacete), julio 1988, pp. 177-187.

- «Marguerite Yourcenar y las espirales del tiempo», Barcarola, 26-27, pp. 239-244.

- «Biographie, autobiographie et quête de soi», Marguerite Yourcenar, Biographie, Autobiographie, pp. 243-252.

- «Marguerite Yourcenar y el eterno retorno», Homenaje a Belloch Zimmermann, Cuadernos de Filología, 1988, pp. 329-334.

- "Voyage et péripétie dans L'Oeuvre au Noir», Voyage et Connaissance dans l'oeuvre de Marguerite Yourcenar, Pisa, 1988, pp. 207-220.

- "La Quête dans Irénée», Henri Bosco, Paris, Corti, 1987, pp. 17-26.

- "Théâtre français et après-guerre espagnole: dix ans de théâtre français à Madrid (1939-1950)", Mélanges au Prof. M. Descotes, Pau, 1988, pp. 461-475.

- «Mer mythologique, mer mythique, mer mystique», Marguerite Yourcenar, Revue de l'Univ. de Bruxelles, 1989, pp. 81-86.

- «La vivacité du tissage: la poétique du réseau dans Feuilles d'observation", Lorand Gaspar, Cahiers de l'Univ. de Pau, 17, 1989, pp. 235-244.

- «La qualité végétale du désir», Francis Jamme. Poète. Actes du Colloque du Cinquantenaire, Pau, J \& D Editions, 1989, pp. 23-32. 
ReAl Ramos, Elena, «L'art de la distance», Marguerite Yourcenar et l'art. L'art de Marguerite de Yourcenar, Publ. de la Soc. Int. d'Etudes Yourcenariennes, Tours, 1990, pp. 275-282.

SAN Miguel, M., «Bilan thématique de l'oeuvre de Francis Jammes», Estudios Franceses, 5, 1989, pp. 121-128.

SANTA i BANYeres, M." Angels, "L'enfermement dans Adrienne Mesurat", Actes du Colloque International Julien Green, Lyon, 1989, pp. 112-120.

- «Souvenirs Pieux o el intento autobiográfico», L'Ull critic, 1, 1989, pp. 47-55.

- "Souvenirs Pieux o el intento autobiográfico", L'Ull critic, 1, 1989, pp. 47-55.

SERnA, Angela, «L'espace simonien. Un jeu avec le mur du langage», Queste, 4, 1988 (1989), pp. 133-143.

SolÀ I SolE, Pere, "D’Adrià a Zénon», L'Ull crític, 1, 1989, pp. $37-46$.

Solé I CASTells, Cristina, "Archétypes du destin et de la fatalité dans Moïra, de Julien Green", Actes du Colloque International Julien Green, Lyon, Presses de l'Université de Lyon III, 1989.

Soler Perez, Ana, «La iniciación como potencial liberador en $\mathrm{La}$ Goutte d'or de Michel Tournier", Queste, 4, 1988 (1989), pp. 209-220.

- «La Dimension mythique comme recherche de l'Absolu», Textos, 1989 (1990), pp. 45-64.

ToME DiEz, Mario, «La actual narrativa francesa I» y «II», Estudios humanisticos (Universidad de León) 9 y 10, 1988 y 1989.

- «La traducción al español de la reciente narrativa francesa», Fidus interpres, Actas de las Primeras Jornadas Nacionales de Historia de la Traducción, II, Univ. de León, 1989, pp. 329338. 
TORRENS, Martine, «Marguerite Yourcenar et Wang-Fo, une vision sur l'art», Estudios Franceses, 5, 1989, pp. 129-142.

Tost, Manuel, Claude Simon. Novelas «españolas» de la guerra y la revolución, Barcelona, Península, 1989.

- Presentació de la novela de Claude Simon, Les Geòrgiques, Barcelona, Ed. 62 i La Caixa.

Usó, María Dolors, "Théâtre et théâtralité dans Mémoires d'Adrien", L'Ull critic, 1, 1989, pp. 27-35.

Verjat Massmann, A., «Del atajo (Sobre Proust)», Barcarola (Albacete), 29, 1988, pp. 199-201.

- Ch. Péguy, El Pòrtic del misteri de la segona virtut, intr. y trad. catalana, Barcelona, Fac. de Teología de Cataluña, 1989.

Valderrama Pascual de Pobil, Amalia Cristina, «La recepción del teatro de Jean Anouilh en los escenarios madrileños entre 1948 y 1975", Investigación franco-española, I, 1988 (1989), pp. 191-217.

Valenzuela Jiménez, Rafaela, "Sobre una versión de $\mathrm{Le} C \mathrm{C}$ metière marin realizada por Carlos Edmundo de Orym, Investigación franco-española, 1, 1988 (1989), pp. 219-242. 


\section{Varios siglos}

Piquer Desvaux, Alicia, «La figura del héroe», El Retorno de Hermes, pp. 118-131.

\section{Historia de las ideas literarias}

GutiÉrez, Fátima, «Epifanias del Imaginario: la leyenda», $\mathbf{L a}$ Leyenda, antropologia, historia y literatura, Madrid, Casa de Velázquez-Univ. Complutense, 1989.

Martín Hernández, Ramiro, "Psychanalyse et littérature (Première Partie). Alfred Adlern, Cuadernos de filología francesa, 3, 1989, pp. 81-110.

Porras MEdrano, Adelaida, «En torno al concepto de utopía», Discurso, 3/4, 1989, pp. 159-167.

Sirvent Ramos, Angeles, Roland Barthes. De las criticas de interpretación al análisis textual, Universidad de Alicante, 1989.

VERJAT, Alain, "Gilbert Durand y la ciencia del hombre», El Retorno de Hermes, pp. 11-19.

YlleRA, Alicia, «Del clasicismo francés a la crítica contemporánea. Historia de las ideas literarias", Epos (Madrid), 5, 1989, pp. 345-369.

\section{Literatura Occitana}

Blanco García, M." Pilar, "La présence de l'eau dans l'oeuvre de F. Mistral, Mirèio», La France latine, 1988.

CASTaÑo Ruiz, Juana, "Variedad cromática en Calendau de Frederi Mistral», Homenaje al Pr. Rubio, I, pp. 219-236.

HeRnÁNDEZ SERNA, Joaquín, "Virgilio en las escuelas medievales: su presencia en las Artes poéticas como "auctoritas" y su recepción por los trovadores I", Homenaje al Pr. Rubio, I, pp. 585-611.

SÁnChez Trigo, Elena, "Caracterización del amigo en las trobairitz», Homenaje al Pr. Rubio, II, pp. 1293-1306. 
Vernhièras, B., A literatura occitana contemporánea. Pequena antoloxía con versión galega, coordenada por --. Santiago, Universidad de Santiago, 1989.

\section{Literatura de expresión francesa Literatura francesa fuera de Francia}

Diaz Narbona, Inmaculada, "Los cuentos de Birago Diop en la literatura africana escrita», Guiniguada (La Laguna) 4, 1988, pp. 19-26.

- Los cuentos de Birago Diop entre la tradición africana y la escritura, Cádiz, Servicio de Publicaciones de la Universidad de Cádiz, 1989.

Halen, Pierre, "D'un étiage poétique assez bas. Ou: La question des genres chez Marcel Thiry", Cuadernos de filología francesa, 3, 1989, pp. 57-79.

Luengo Alburquerque, Elisa, La literatura fantástica en Bélgica durante el siglo $X X$ : las recurrencias narrativas, Cáceres, Universidad de Extremadura.

Popa-Lisseanu, Doina, «Problemas de recepción de un escritor de expresión francesa: el caso de Panait Istrati», Epos, 4, 1988, pp. 299-317.

Porras Medrano, Adelaida, «Una lectura de La Nuit sacrée de Tahar Ben Jelloun", Didáctica, 1, 1989, pp. 159-167.

- «Le roman ethnographique maghrébin: Le Fils du pauvre de Mouloud Feraoun", Estudios de lengua y literatura francesa, 3, 1989, pp. 213-223.

\section{Literatura comparada}

BenoIT MORINIÈRE, Claude, "L'influence espagnole dans Les Contents d'Odet de Turnèbe', Echanges culturels dans le Bassin 
occidental de la Méditerranée (France, Italie, Espagne), Colloque organisé par l'Univ. de Toulouse-Le Mirail avec la coll. de l'Univ. de Ferrare, mai, 1989, Toulouse, Presses Univ. de Toulouse, 1989, pp. 239-248.

Cobos CASTRo, Esperanza, «Ductilidad y contingencias de la transtextualidad. Reflexiones en torno a $\mathrm{Al}$ fin se paga todo (Maria de Zayas), L'Adultère innocent (Scarron) y Le Philtre (Stendhal)», Investigación franco-española, 1, 1988 (1989), pp. 67-99.

GALMES DE FUENTES, Alvaro, «El Libro de los engaños y el fabliau francés de Auberée», Homenaje al Pr. Rubio, I, pp. 431-439.

Jimenez Plaza, Dolores, "Les Corrivaux de Jean de la Taille et la Comedia de Sepúlveda; deux pratiques théâtrales différentes sur un même thème», Echanges culturels dans le bassin occidental de la Méditerranée..., pp. 223-230.

LÓPEZ JiMÉNEZ, Luis, «La muerte de Carmen de S. de Madariaga y Carmen de P. Mérimée: fidelidad y recreación", Filología Románica, 5, 1987-1988.

- «Paz, Apocalipsis y Misterio de Toledo en cuatro autores franceses contemporáneos, Larco, Malraux, Tharand, Barres», Toledo, ¿ciudad viva? ¿ciudad muerta? Toledo, Colegio Universitario, 1988, pp. 501-512.

ReAL RAMOS, Elena, «Milosz et Valle-Inclán. Echos et discordances", Fins de Siècle: terme-évolution-révolution, Actes du Congrès de la Sociéte française de Littérature générale et comparée, Presses Univ. du Mirail, 1989, pp. 547-556.

- «L'intrigue et les personnages dans la Comedia et Les Corrivaux», Echanges culturels dans le bassin occidental de la Méditerranée..., pp. 231-237.

Torres Monreal, Francisco, «El teatro de Garcia Lorca en Francia (1938-1973)», Homenaje al Pr. Rubio, II, pp. 13471369.

Vidal Garcia, Francisco, «Nietzsche, Malraux y la Muerte de Dios. La vivencia de una época de crisis», Homenaje al Pr. Rubio, II, pp. 1469-1485. 